is very much warranted to shed more light on the cytogenetic and phylogenetic relationships within the subgenus Anopheles ${ }^{9}$.

Zusammentassung. Es werden verschiedene tropische Anophelesarten, besonders die orientalische, cytogenetisch untersucht. Es wird eine Standard-Chromosomenkarte von Anopheles barbirostris van der Wulp (Typ der Barbirostris-Gruppe einer orientalischen Region und zur Serie Myzorhynchus, der Untergattung Anopheles ge- hörend) als erste der Serie orientalischer Anophelesarten vorgeschlagen.

B. N. Chowdaiah, T. T. Avirachan and P. L. SeEtharam

Department of Zoology,

Central College, Bangalove University,

Bangalove (India), 29 August 1969.

9 This study has been supported by a grant from the World Health Organization.

\title{
The Spectral Sensitivity of the Tail of Urodacus, a Scorpion
}

Recordings of spike activity in the nerve cord have revealed an extraocular light sense in an Australian scorpion, Urodacus novae-hollandiae. 1 . It was shown to be sensitive to light in the range from long UV to green. The present investigation is an attempt to determine its spectral sensitivity quantitatively.

The recordings were made with hook electrodes from the mesosomal nerve cord, between the second and the third mesosomal ganglion. The cord was severed ahead of the recording site and the neural vessel was stripped from the connectives. Illumination was restricted to the metasoma (the 'tail'). The light source was a heat-filtered $150 \mathrm{~W}$ xenon arc whose intensity was controlled with a neutral density wedge or, in the UV, with metal sieves. Wavelengths were selected by means of Schott FIL interference filters in the visible range and a Schott UG2 ( $2 \mathrm{~mm}$ ) filter in the $\mathrm{UV}$; their transmission was calibrated with a thermopile and the readings divided by the wavelength in order to obtain energy values proportional to the number of quanta.

The preparations were kept in the dark except for the test flashes of about $4 \mathrm{sec}$ duration. The intervals between flashes were sufficient to ensure complete recovery, as indicated by previous tests. Spikes were counted from filmed records for the third second after the onset of light. Preliminary experiments had shown that at the intensities used the spike frequency could be regarded as a linear

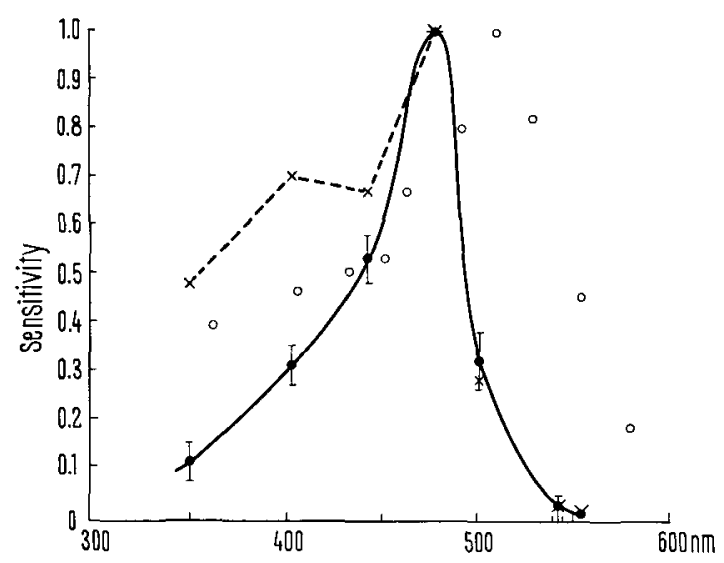

Spectral sensitivity of the extraocular light sense of Urodacus (means of 5 duplicate determinations \pm standard error). $\times$, values corrected for cuticular transmission; 0 , values for scorpion median eye (MACHAN ${ }^{2}$ ). function of $\log \mathrm{I}$. Consequently each wavelength was tested at a number of intensities, the spike frequencies were plotted against $\log I$ and a straight line drawn through the points. This resulted in a family of 7 lines, one for each wavelength. Spectral sensitivity curves, based on a standard response taken as one-half the maximum response of the preparation, were derived from this graph. The spectral response curves, based on equal energy stimuli, were very similar. 5 prepatations were used with duplicate determinations in reverse order of stimuli.

The peak of the sensitivity curve (Figure) lies in the blue-green region at about $480 \mathrm{~nm}$. The data for median eyes of a number of other scorpion species published by $\mathrm{MACHAN}^{2}$ are plotted for comparison. The tail curve is rather narrower; it is in fact narrower than the typical retinene pigment curve ${ }^{3}$. A yellow filter, reducing the sensitivity in the blue and long UV-ranges, would account for the narrowness of the curve and specifically for the low values at short wavelengths. A tail segment can be described as a box with sclerotized edges and panels of unsclerotized cuticle. These transilucent panels are yellowish in colour and determinations of their spectral transmission confirm that it drops steadily and markedly towards the shorter wavelengths. The transmission values were used in plotting the corrected curve. This curve is comparable with that of scorpion median eyes ${ }^{2}$, although shifted towards the left. The shoulder is reminiscent of similar shoulders and secondary peaks reported from many invertebrate eyes ${ }^{4}$.

Zusammenfassung. Die spektrale Empfindlichkeit des extraokularen Lichtsinnes des australischen Skorpions Urodacus wurde bestimmt. Das Maximum liegt im Bereich von $480 \mathrm{~nm}$. Die Einberechnung der Kutikulartransmission verändert die Form der Kurve, besonders im UV, aber das Intensitätsmaximum bleibt dasselbe.

K. T. ZWICKY

Department of Zoology,

University of Western Australia,

Nedlands (Western Australia), 24 September 1969.

1 K. T. Zwicky, Life Sci. 7, 257 (1968).

2 L. Machan, J. exp. Biol. 49, 95 (1968).

3 H. J. A. Dartnall, Br. med. Bull. 9, 24 (1953).

4 G. S. Wasserman, Vision Res. 9, 611 (1969). 